\title{
Guided Image Art Therapy as a Problem-based Learning Tool for Stress Reduction within the Context of a Scientific Literacy Course
}

\section{Hannah Cooke-Ariel}

Department in Physical Sciences, Lynn University, Boca Raton, Florida, USA

*Corresponding author: Cooke-Ariel H, Lynn University, Boca Raton, Florida, USA, Tel: 561-313-8456; E-mail: HAriel@lynn.edu

Rec date: Mar 23, 2015; Acc date: Apr 11, 2015; Pub date: Apr 15, 2015

Copyright: (C) 2015 Cooke-Ariel H. This is an open-access article distributed under the terms of the Creative Commons Attribution License, which permits unrestricted use, distribution and reproduction in any medium, provided the original author and source are credited.

\begin{abstract}
This research article describes a method for integrating stress reduction methods and skills into a university curriculum with the dual intention scientific literacy instruction and development of lifelong skills in biofeedback regulation and stress reduction.

Twenty-one university students enrolled in a scientific literacy course were introduced to Bloom's Taxonomy of educational objectives for higher order thinking processes, and subsequently encouraged to apply these higher cognitive levels of thinking to scientific method and scientific inquiry. Students and instructor designed a study, Pulse "As a Surrogate Marker for Biofeedback Regulation", in which students became the study subjects. Students were instructed on taking pulse measurements and were assessed by instructor and by laboratory partner for skill in pulse measurement.

In the second phase of this case-control study, students participated in a 50 minute guided image art therapy session. Each student acted as his/her case control, measuring pulse pre-art therapy to establish a baseline, and then measuring pulse post-art therapy session.

Results revealed a clinically significant reduction in pulse in 19 of 21 student subjects. A clinically significant difference in pulse was set at greater than 5 beats per minute in difference of the mean comparison of pulse preand post-art therapy session.

In conclusion, this exercise fulfilled the requirements of instruction in scientific inquiry, while offering students new mechanisms for controlling stress and regulating their individual biofeedback mechanisms. This model may serve as a template for instructional courses. The exercise was well received by students.
\end{abstract}

Keywords: Guided imagery; Stress reduction; Instructional methods; Curriculum

\section{Introduction}

Primary outcome measures for scientific literacy include competency in critical literature evaluation and quantitative reasoning. A learner who achieves these competencies will be skilled not only in reading and comprehending scientific literature, but, more importantly, in differentiating between well designed, well described research, and literature of an inferior quality. Transferring this skill to a learner is challenging [1]. Methods to actively engage the learner in processing and applying these skill sets are herein presented.

The learners enrolled in an undergraduate university level scientific literacy course are presented with three major goals:

To meet a primary outcome of processing key scientific theories and practices identified as important to evolution of scientific literacy as determined by a core group of university educators.

To assimilate, integrate and apply the scientific method to the given science curriculum.

To achieve a higher-order cognitive process of critical literature evaluation.
In order to gain higher-ordered thinking skills, learners were presented with seminars on the scientific method, and applications of Bloom's Taxonomy of Higher Ordered Thinking Skills [2]. Learners were given concrete examples of sequential steps in the Scientific Method, and mechanisms for incorporating higher-ordered thinking skills within the scientific method. Students were also presented with an overview of inductive and deductive reasoning, with relevance to the scientific process.

In the second phase, students were introduced to the constructs of Problem-Based learning, wherein learners are challenged to apply Bloom's Taxonomy to critically evaluate a given problem. An additional component challenged learners to apply the scientific method to solve the problem.

The problem chosen for learner and educator demonstration was: Pulse "As A Surrogate Marker For Effective Biofeedback and Cardiovascular Relaxation". Learners were subsequently taught about the cardiovascular system and the importance of Biofeedback and the Relaxation Response [3-5]. Learners actively participated in a laboratory session on pulse measurement. Technique for pulse measurement was reviewed and demonstrated first by the educator, then by learners. Learners validated pulse measurement by taking the average of three measurements themselves, and then allowing their lab partner to take the average of three pulse measurements for them. This 
Page 2 of 3

was the first exercise in quantitative reasoning and quantitative analysis. Learners recorded average pulse, discussed precision and standard deviation, and developed an acceptable level of variation in pulse measurements.

Learners then graphed average pulse measures for each individual $(\mathrm{n}=1)$, and for all learners $(\mathrm{N}=21)$.

After gaining competency in baseline skills in quantitative reasoning in the form of statistical analysis, and after becoming adept in pulse measurement, students were introduced to a key scientist, Carolus Linnaeus, the father of taxonomy. Learners were instructed to select a specimen from the environs and bring it to the subsequent laboratory session, which would involve art therapy, with the subject matter to be creatively drawn being their specimen. They also were instructed to research and provide the binomial nomenclature for the specimen.

Prior to the laboratory session, learners were detailed on elements of art therapy as a means of effective biofeedback leading to cardiovascular relaxation. Learners were actively engaged in the development of a Null Hypothesis and Alternative Hypothesis. The
Null Hypothesis was that there would be no significant difference in pulse before and after art therapy. The Alternate Hypothesis was that there would be a clinically significant difference in pulse before and after art therapy. Learners were instructed on the meaning of significant difference and assisted in determining what would be considered a clinically significant difference in pulse. A clinically significant difference in pulse was set at 5 beats per minute. Pulse was selected as a surrogate marker for cardiovascular relaxation. The study design and methodology was modelled after Murray Mittleman's casecontrol study design, where subjects act as their own controls, and are observed before and after an "exposure", or effect [6].

In the next laboratory session, learners were provided with art media for completion of a fifty minute art therapy session. Learners measured and recorded pulse before and after the art therapy session. Results are recorded in Table 1. Learners were guided through a data analysis, determining mean, median and mode for their data. Finally, a difference between the means was calculated and found to be, by definition, clinically significantly different pre- and post-art therapy session.

\begin{tabular}{|c|c|c|}
\hline \multirow[b]{2}{*}{$\mathbf{N}$} & \multicolumn{2}{|c|}{ Pulse (Beats per minute) } \\
\hline & Pre-Pulse Rate & Post-Pulse Rate \\
\hline 1 & 56 & 45 \\
\hline 2 & 60 & 50 \\
\hline 3 & 65 & 60 \\
\hline 4 & 66 & 60 \\
\hline 5 & 66 & 60 \\
\hline 6 & 66 & 60 \\
\hline 7 & 68 & 62 \\
\hline 8 & 68 & 63 \\
\hline 9 & 70 & 64 \\
\hline 10 & 71 & 68 \\
\hline 11 & 72 & 70 \\
\hline 12 & 72 & 72 \\
\hline 13 & 76 & 72 \\
\hline 14 & 76 & 72 \\
\hline 15 & 80 & 72 \\
\hline 16 & 81 & 75 \\
\hline 17 & 84 & 78 \\
\hline 18 & 84 & 78 \\
\hline 19 & 88 & 81 \\
\hline 20 & 90 & 82 \\
\hline 21 & 108 & 92 \\
\hline
\end{tabular}


Citation: Hannah CA (2015) Guided Image Art Therapy as a Problem-based Learning Tool for Stress Reduction within the Context of a Scientific Literacy Course. Altern Integr Med 4: 190. doi:10.4172/2327-5162.1000190

Page 3 of 3

\begin{tabular}{|l|l|l|}
\hline & Pre & Post \\
\hline Range & $56-108$ & $45-92$ \\
\hline Mean & 74.6 & 68.4 \\
\hline Median & 72 & 70 \\
\hline Mode & 66 & 60,72 \\
\hline Difference of the Means: 6.2. & \\
\hline Null hypothesis is rejected. Alternate hypothesis of clinically significant difference in pulse is accepted. \\
\hline
\end{tabular}

Table 1: Participants Pre- and Post-pulse rate assessment per minute.

Learners were asked for their subjective input on this exercise. All students were actively engaged throughout the process and all students stated that the exercise was effective in accomplishing the three major goals set forth at the beginning of the exercise.

This prospective, hand-on approach to teaching quantitative reasoning and data analysis was well received. This methodology offers active involvement in the learning process, and assists in development of critical analytical skills. Methods such as these reinforce mandated national benchmarks requiring a baseline competency in quantitative reasoning and data analysis of all entry level university students, particularly those in the science discipline.

This novel approach to instilling key educational concepts while actively engaging learners may be employed in a multitude of settings to accomplish the same goal. Students were asked to evaluate this particular Scientific Literacy course using the ETS SIR II (Student Instructional Report II). The SIR II is designed to:

Identify areas of strength and/or areas for improvement,

Provide feedback from students,

Provide information on recent teaching methods used in class,

Provide measures of effective teaching.

Responses are reported in percentages and averages are reported as overall mean and comparative mean. The overall mean represents the performance of the individual instructor's teaching. The comparative mean is an average based on user data from a sample of 4 year colleges and universities between the years of 2003-2010. The comparative means for 4-year institutions was obtained by averaging the mean ratings for 238,471 classes from 111 institutions. All overall means were above the comparative means for this Scientific Literacy course. A more detailed discussion is given Supplementary file.

\section{Conclusion}

The problem-based learning approach to instruction in scientific literacy was found to be moderately to very effective, and more effective than the comparative mean for the SIR II Assessment Tool. The laboratory exercises represent the problem-based learning sessions. These were found by 71 percent of students to be very effective, and by 28 percent of students to be effective. Instructional methods such as this problem-based learning approach to teaching scientific literacy engages students in active learning, through casestudies, simulations and guided, measured exercises to promote higher levels of cognitive thought, synthesis and application of concepts learned.

\section{References}

1. Koppal M, Caldwell A (2004) Meeting Challenge of Scientific Literacy: Project 2061. Efforts To Improve Science Education. Cell Biology Spring: 3.

2. Bloom H. Taxonomy of Educational Objectives: The Classification of Educational Goals.

3. Http://www.webmd.com/a-to-zguides/biofeedback-therapy-usesbenefits.

4. Http://www.helpguide.org/harvard/mindfulness.htm.

5. Http://www.webmd.com/heart-disease/pulse-measurement.

6. Mittleman M (1995) Control sampling strategies for case-crossover studies: an assessment of relative efficacy. American Journal of Epidemiology 142(1): 91-98. 